Original scientific paper

\title{
FLOW CHARACTERISTICS OF OIL-GUIDING SPLASH LUBRICATION: SIMULATION AND EXPERIMENT STUDIES
}

\author{
Yin, M. ${ }^{* *}$; Xu, L. J. ; Dai, Y..,\#; Yang, D. ${ }^{* *} \&$ Zhu, X.* \\ * College of Mechanical and Electrical Engineering, Central South University, Changsha, China \\ ${ }^{* *}$ Hunan Aviation Powerplant Research Institute, AECC, Zhuzhou, China \\ E-Mail: 210143@csu.edu.cn ( ${ }^{\#}$ Corresponding author)
}

\begin{abstract}
Based on the computational fluid dynamics (CFD) method, the performance of the oil-guiding cylinder, a key component in a novel splash lubrication system of the helicopter main reducer, was investigated in terms of three different kinds of structures. The pressure and velocity distribution characteristics were firstly simulated and analysed. The numerical simulations indicated that the oil free surface formed in the rotating cylinder was a paraboloid, meanwhile the structure without a bottom flange can achieve the splash effect constantly. Furthermore, the experimental findings agreed well with the numerical results, it was verified that the cylinder with a cylindrical-shaped lower wall surface gave a better lubrication performance than the conical-shaped. Besides, it was found that the oil volume increased with the rotating speed and oil level increasing, and the geometry parameters of the oil-guiding cylinder and the operating conditions have a great effect on the oil-guiding splash lubrication performance.

(Received in December 2020, accepted in March 2021. This paper was with the authors 3 weeks for 1 revision.)
\end{abstract}

Key Words: Splash Lubrication, Computational Fluid Dynamics, Forced Vortex, Main Reducer, Oil-Guiding Cylinder

\section{INTRODUCTION}

Under the low or moderate speed conditions, splash lubrication method is widely used in the intermediate gearbox of helicopters. Over the last couple of decades, numerous studies have focused on the churning behaviour, Daily and Nece [1] investigated the phenomenon of flow caused by partially submerged rotating discs, and then the drag torque was theoretically predicted by Mann and Marston [2]. Until now, the comprehensive researches and analyses have been made on the churning behaviours for various gears and bearings [3-5].

Nowadays, many scholars exploited CFD programs to study the various flow field characteristics [6-13], including the gear lubrication behaviour and churning power losses, a typically load-independent power losses. For instance, Concli et al. [11-13] had carried out quite a lot of works that showed the effectiveness of CFD methods for the characterization and the optimization of the gear windage and churning losses. Hu et al [14] established the CFD model of spiral bevel gearbox with an oil guide device and box housing and predicted the churning losses of spiral bevel gears under splash lubrication. By leveraging the finite volume CFD method, Liu et al [15] were engaged in the determination of the oil distribution and churning losses of gearboxes and compared well with the experimental findings by a specific test rig. Laruelle et al. [16] presented a theoretical analysis about churning power losses of a spiral bevel gear, and the experimental values obtained by the test bench shows a good agreement with the theoretical results. Similar experiments for a planetary gear set were done by Boni et al. [17], a specific test facility was developed to explore the churning losses of the gear set. The housing structure and shape of the gearbox also significantly influenced the splash lubrication performance. Chen and Matsumoto [18] constructed a rotational test rig to investigate the influence of casing wall shape on churning power losses, furthermore, the relative position of gears with respect to the casing wall is a non-negligible factor and was also investigated. Oil distribution is widely considered to be one of the evaluation indicators of 
lubricating effect. Peng et al. [19] studied the oil flow characteristics in splash lubricated hypoid gearbox via CFD method, especially for oil distribution and churning losses. The CFD approach is accepted to be an efficient tool to address the churning behaviour of gears. Concli et al. [13] investigated the effect of operating conditions and structural parameters on the churning losses of ordinary gears. More than that, Concli and Gorla [20] further developed an effective tool to calculate the churning losses, and the integrated approach has a good agreement with experiments.

All of these always focus on the conventional splash lubrication method. As for the small helicopters, limited to the apace structure of the main reducer and demands of lightweight, the oil-guiding splash lubrication is adopted in the geared system. In the oil-guiding splash lubrication system, the oil splashing behaviour is formed by forced vortex, and the oil free surface will be formed a paraboloid. The oil distribution is determined by the forced vortex in connection with the rotating speed, wall height, and diameter of the oil-guiding cylinder. The investigations on the forced vortex are relatively scarce, Hatami and Ganji [21] improved the solution of a spherical particle in the forced vortex and proposed a new fast calculation formulation.

This paper aims to address the prediction of the complex forced vortex formed by the rotating oil-guiding cylinder with the aid of the CFD method. Moreover, a specific test rig for the oil-guiding splash lubrication is established, with which the experiments are carried out to verify the numerical investigations.

\section{CFD FORMULATION}

\subsection{Forced vortex}

The forced vortex is a fluid motion generated by a rotating object. In the forced vortex, the liquid rotates at a constant acceleration without shear stress and remained stable. Once the angular acceleration drops to zero, the forced vortex rotates at a constant angular velocity $\Omega$, the corresponding tangential velocity at radius $r$ is $\Omega r$. Given that there is no relative movement, the forced vortex can be regarded as an inviscid flow. By integrating and reforming the NavierStokes equation, the pressure distribution of the forced vortex can be written as:

$$
p-p_{0}=\frac{1}{2} \rho \Omega^{2} r^{2}-\rho g\left(z-z_{0}\right)
$$

where $p$ indicates the pressure of the free surface, $p_{0}$ represents atmospheric pressure, $z_{0}$ denotes the minimum distance from the bottom of the container to the free surface.

According to Eq. (1), in the forced vortex, the free surface is a paraboloid, as shown in Fig. 1 a. If $p=p_{0}$, Eq. (1) can be simplified as:

$$
z-z_{o}=\frac{\Omega^{2} r^{2}}{2 g}
$$

Then, the maximum free surface height $z_{\max }$ is:

$$
z_{\max }=H+\frac{\Omega}{2 g}\left[\left(R-\frac{1}{4}\right)^{2}-\frac{1}{16}\right]
$$

where $H$ is the oil height when the vortex is stationary, and $R$ represents the vortex radius.

In the oil-guiding splash lubrication system, the shape of the oil-guiding cylinder is shown in Fig. 1 b. The cylinder is partially immersed in the oil and rotates it around its own axis, the lubricating oil is driven to form a forced vortex. 


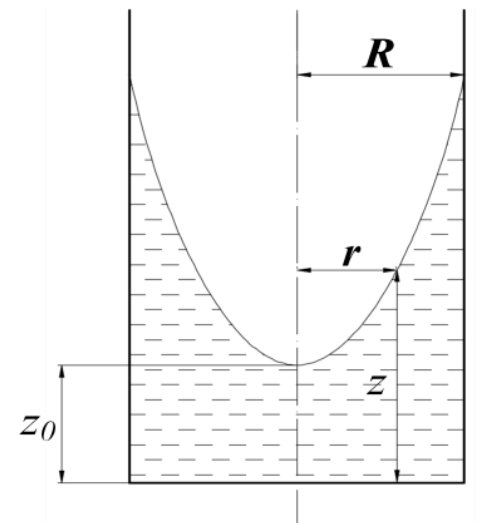

a) Forced vortex

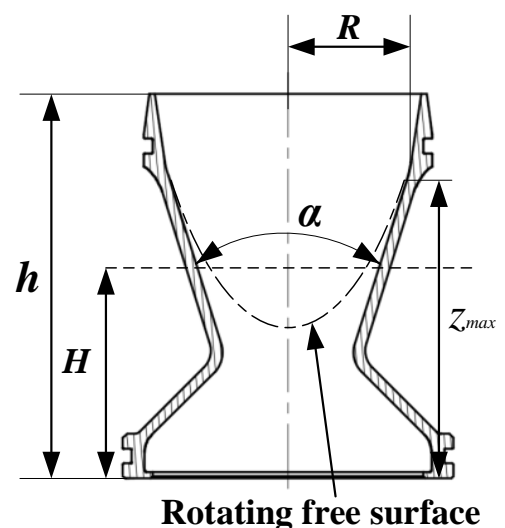

b) Oil-guiding cylinder

Figure 1: Free surface of the forced vortex and free surface in the oil-guiding cylinder.

Aim to guide the lubricating oil, the crucial issue is how high the internal free surface could reach. According to Eq. (3), the highest position $z_{\max }$ is the product of oil level, rotating speed, and the radius of the cylinder. But more than that, the shape of the cone wall and the height of the cylinder will influence the oil guiding behaviour as well. Subject to the opening bottom of the cylinder, the pressure at the bottom of the cylinder will not meet the requirements of Eq. (1). CFD method is prior to investigating the oil guiding behaviour.

\subsection{CFD geometry}

Spiral bevel gears are adopted in the main reducer for small helicopters, as shown in Fig. 2. The input and output shafts are both hollow shafts, and the output shaft is connected to the rotor. The bottom of the rotor shaft is equipped with an oil-guiding cylinder. The inner surface of the cylinder is a biconical-shaped surface, and there are several oil-jet holes along the circumference in the top of the cylinder. When the rotor shaft rotates, the lubricating oil is simultaneously driven to rotate by the cylinder, forming a complex vortex close to the forced vortex. The oil climbs up to reach the vicinity of the oil-jet holes. Owing to the centrifugal force, the oil is splashed through the holes to the friction pairs (including the spiral bevel gears, splines, and bearings). At the same time, the oil is splashed into the inner cavity of the input shaft and flows through the lubricating hole of the input shaft, finally reaching the clutch and bearings. To verify the feasibility of this novel lubrication system, the flow characteristics in the oil-guiding cylinder need to be investigated. The churning behaviour of incompressible flow in the oil-guiding splash lubrication system is mainly concerned.

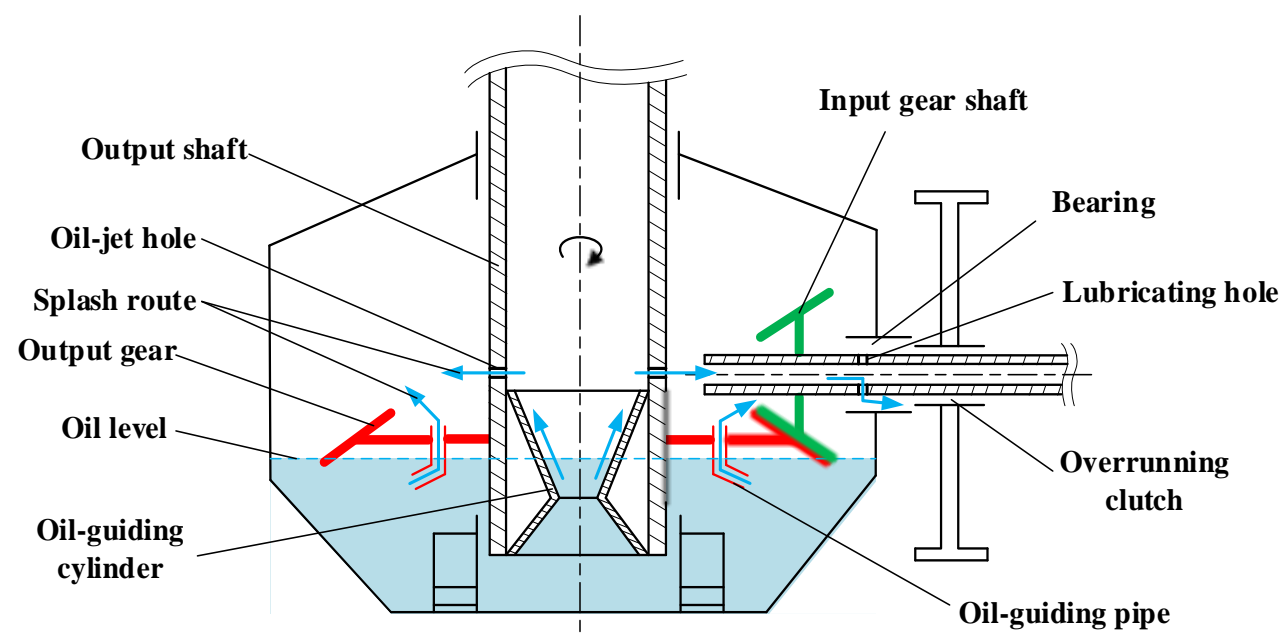

Figure 2: Schematic diagram of a helicopter main reducer splash lubrication system. 


\subsection{CFD modelling and numerical setup}

Three kinds of oil-guiding cylinder models with different structures are established, as shown in Fig. 3 a. Model A is biconical-shaped, while model B and C with different lower part structures are designed. The upper cone angle of all models is $35^{\circ}$. The cone angle of the lower conical surface for model $\mathrm{A}$ is $90^{\circ}$. The inner surface of model $\mathrm{B}$ is conical. As for model $\mathrm{C}$, the lower part structure is a cylindrical surface with a diameter of $32 \mathrm{~mm}$. The distance from the bottom of the oil-guiding cylinder to the bottom of the oil pool is $15 \mathrm{~mm}$.

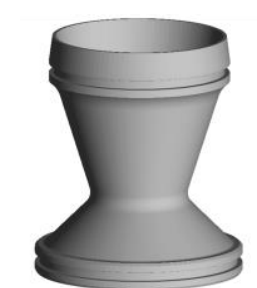

Model A

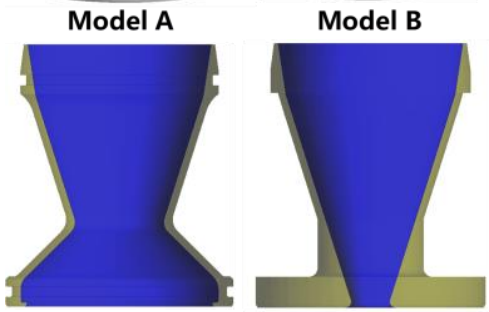

a) Simulation models

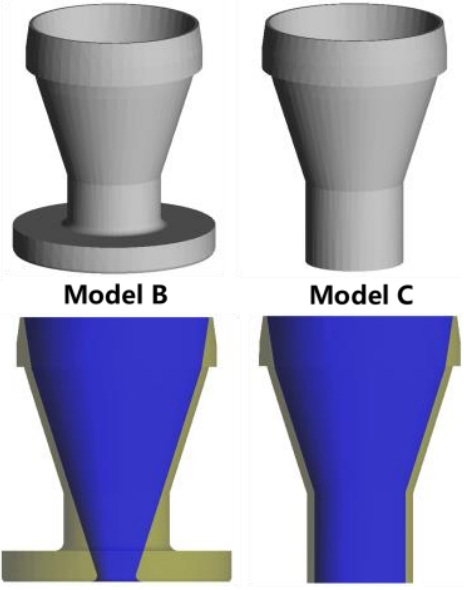

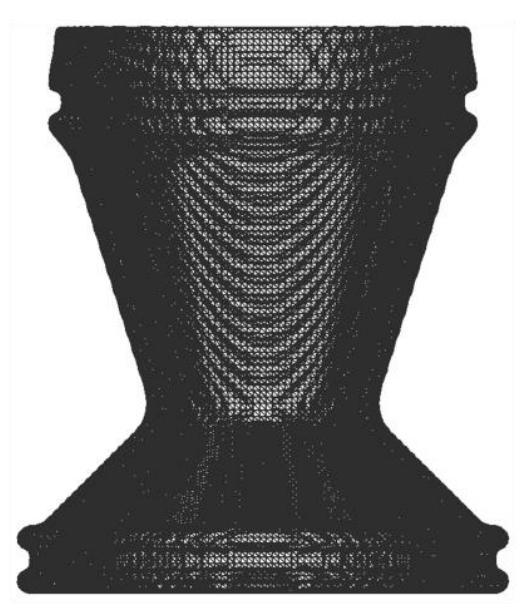

b) Calculation mesh of model A

Figure 3: Simulation models and calculation mesh of the oil-guiding cylinder.

CFD method was adopted to study the churning behaviour of the oil-guiding cylinder. The rotating speed of the cylinder around the $z$-axis is set to $530 \mathrm{rpm}$. The density of lubricating oil is $0.97 \mathrm{~g} / \mathrm{cm}^{3}$, viscosity is $0.0075 \mathrm{~N} \cdot \mathrm{s} / \mathrm{m}^{2}$, and the oil level is set to $50 \mathrm{~mm}$. The RNG $k-\varepsilon$ model capable of addressing external flow problems of complex geometry is adopted in this paper.

With fractional area/volume obstacle representation technique, a porous-body mesh model is developed to simulate the splash lubrication and the hexahedral grid is used for mesh generation. As in Fig. 3 b, the number of grids in the computation domain is 4,012,910, and the maximum adjacent cell size ratio is 1.01 in three directions of the Cartesian coordinate system. The symmetry boundary applies a zero-gradient condition at the boundary as well as a zerovelocity condition normal to the boundary. It is generally used to simulate the sliding wall in viscous flow. The restart data interval is set to 0.1 seconds. This paper focuses on the influence of the cylinder structure on oil-guiding splash lubricating performance, and the primary indicator to evaluate the lubricating performance is the amount of oil feeding. Therefore, a monitoring surface is set to obtain the flow rate through the top plane of the oil-guiding cylinder for measuring the lubrication performance.

\section{NUMERICAL SIMULATIONS}

Fig. 4 shows the pressure distribution of the flow field for model A at different times. At $0.3 \mathrm{~s}$, the oil rotates with the inner surface, so the oil flows to the periphery of the free surface because of the action of centrifugal force, and climbs upward along the inner surface. Meanwhile, the velocity of the swirling flow increases, and the oil forms to be similar to a forced vortex. A paraboloid free surface is gradually generated inside the cylinder. At $0.7 \mathrm{~s}$, a small amount of oil reached the top of the cylinder, and the liquid level drops. Furthermore, at $0.9 \mathrm{~s}$, the liquid level is lower than the minimum diameter position of the cylinder. At $1.5 \mathrm{~s}$, the residual oil in the upper part of the cylinder is continuously thrown out of the cylinder, and the internal liquid level continues dropping. Till the end of the simulation, most of the oil in the upper part of the 
cylinder is thrown out, and the internal liquid level drops to the position close to the bottom of the oil pool, and the oil is not continuously supplied to the top part. From this, the pressure difference influences the fluid flow and changes the oil quantity inside or outside the cylinder, the forced vortex formed by the rotating cylinder with the bottom opened is very different from that generated by a rotating vessel with a closed bottom.

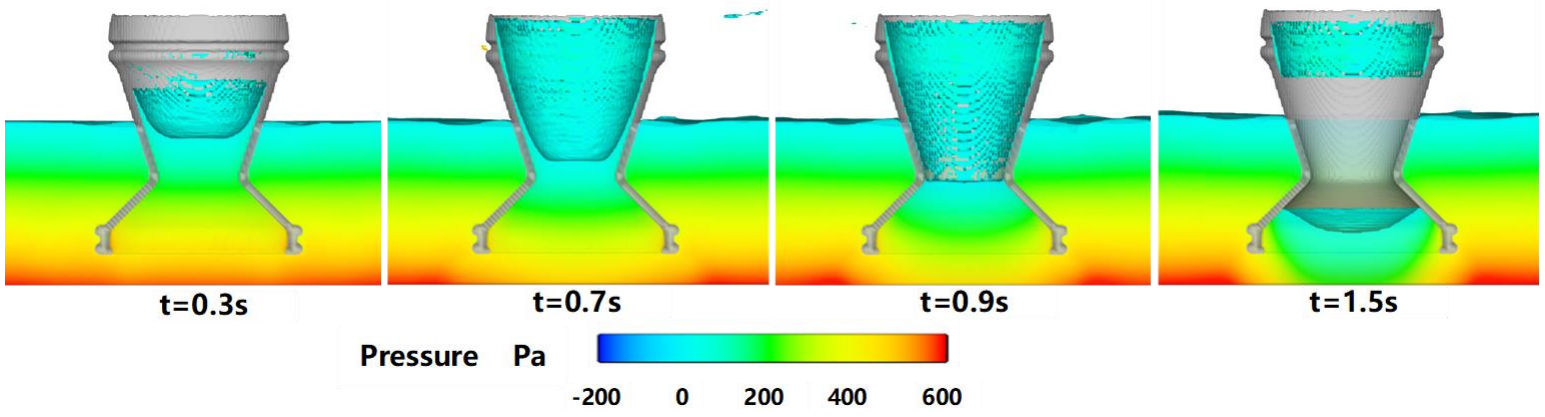

Figure 4: Pressure distribution of model A.

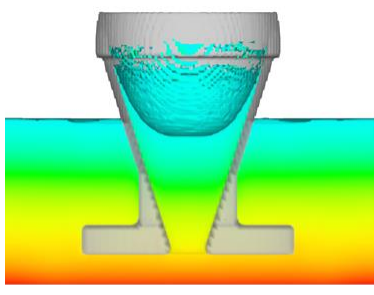

$t=0.3 s$

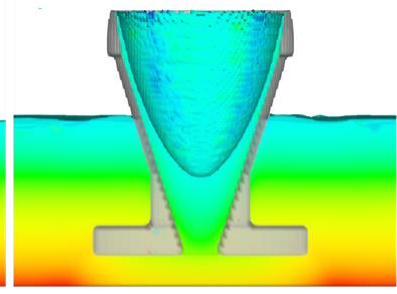

$t=1 s$

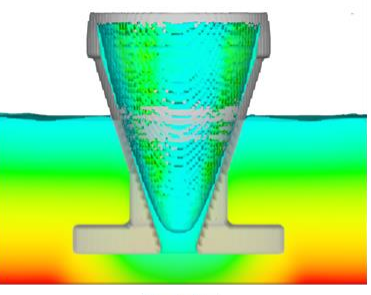

$t=2 s$

Pressure

Pa

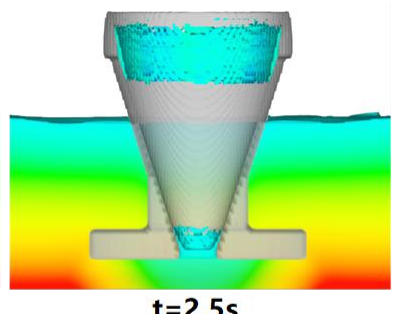

$t=2.5 s$

Figure 5: Pressure distribution of model B.

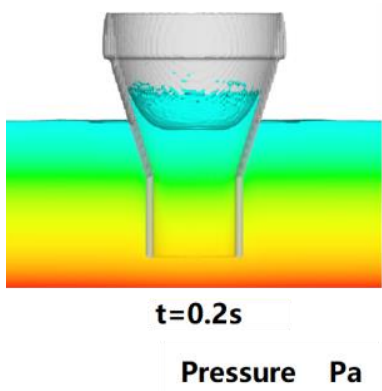

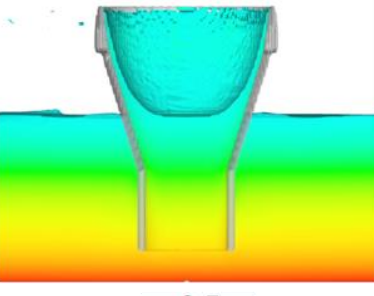

$t=0.5 s$

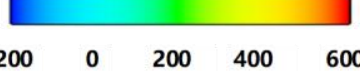

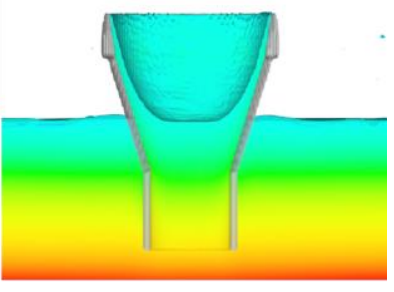

$\mathbf{t}=\mathbf{2 s}$

Figure 6: Pressure distribution of model C.

Similar to model A, the change laws of oil level for model B are shown in Fig. 5. From $0.3 \mathrm{~s}$ to $2 \mathrm{~s}$, the oil was separated by centrifugal force and formed a paraboloid free surface. Oil rotates and climbs up as the cylinder is rotating. However, the internal free surface is finally fallen to the bottom of the cylinder, oil could not be fed up continuously.

The pressure distribution of the flow field for model $\mathrm{C}$ at different times is depicted in Fig. 6. At $0.5 \mathrm{~s}$, the oil reaches the top and forms a paraboloid-shaped free surface. The internal free surface is unchanged over time, and the oil splashes out from the top, the internal flow field reaches a dynamic equilibrium state.

In all models, the oil pressure near the cylinder is always greater than the centre of rotation at the same height. This is because the oil flows near the wall by the centrifugation, and results in the oil accumulation near the wall. It is also consistent with the pressure distribution of the forced vortex. 


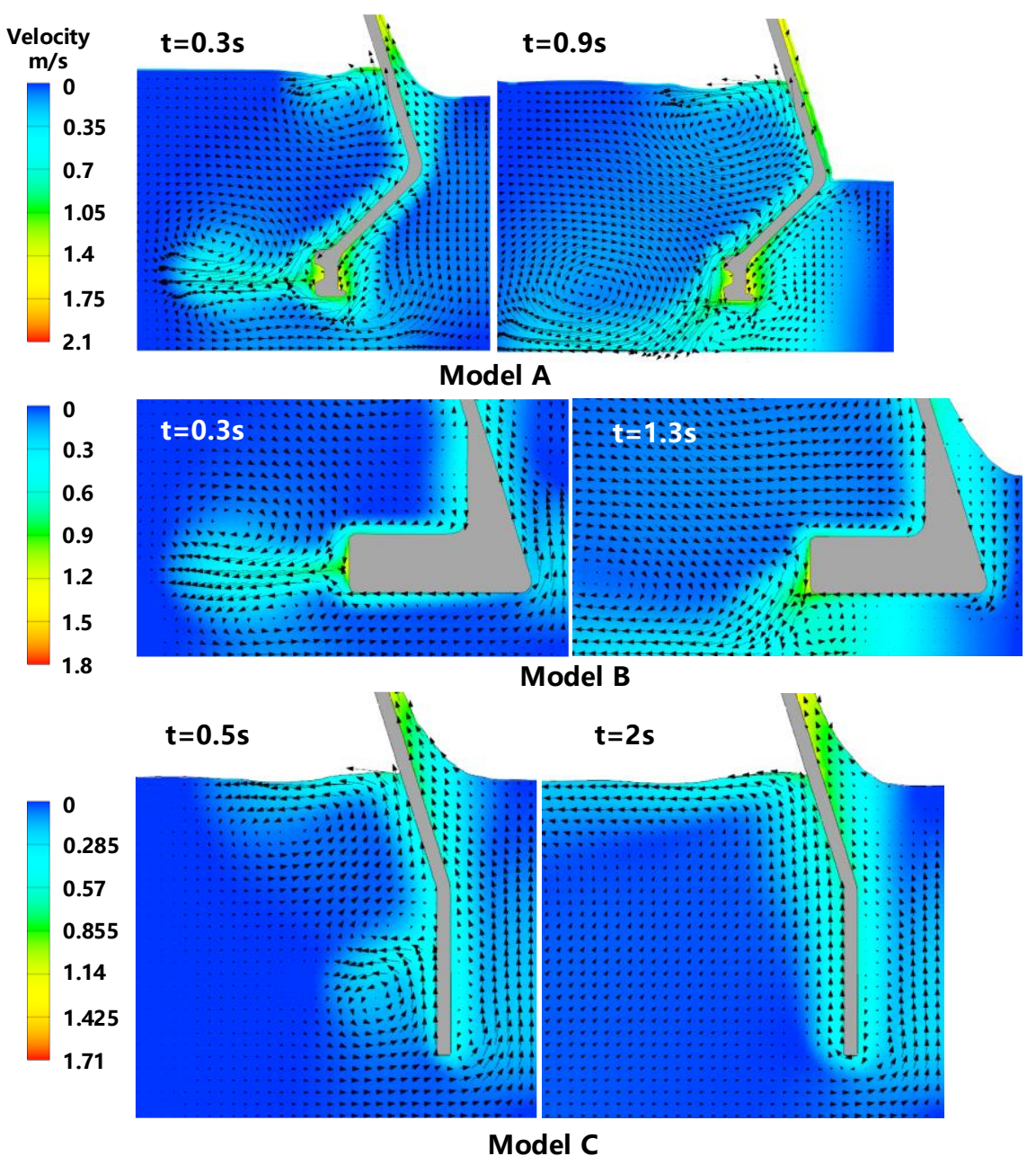

Figure 7: Velocity distribution at $x=0 \mathrm{~mm}$.

Additionally, the velocity distribution of the longitudinal section is shown in Fig. 7. It can be found that the greater velocity appears near the cylinder wall. As the oil rotates along with the cylinder, it is centrifuged and flows upward or downward along the wall.

For model A, the oil near the inner wall in the plane of $z=30 \mathrm{~mm}$ tends to flow upward, while the lower oil tends to flow downward, and the velocity of lower oil is higher. So, the oil is transported downward in the cylinder. The oil in the oil pool always flows to the wall, meanwhile, the oil is continuously discharged from the bottom of the cylinder, and there is no sufficient oil to replenish the centre area of the inlet at the cylinder bottom. At $0.3 \mathrm{~s}$, the oil is supplied through the low-speed area under the cylinder. However, after $0.7 \mathrm{~s}$, the high-speed oil from the inner and outer wall converges in the edge area of the cylinder bottom and flows downward in an oblique direction. The low-speed area is separated by the high-speed turbulence, so the low-speed oil could not flow inside the cylinder, the disturbing flow hinders the oil replenishment of the oil-guiding cylinder.

For model B, it can be observed that at $0.3 \mathrm{~s}$, the oil passes through the low-speed area under the bottom flange. Then at $0.8 \mathrm{~s}$, the bottom area is surrounded by the high-speed flow, so the internal area is hindered by the disturbing flow and could not be replenished. At $1.3 \mathrm{~s}$, the speed of oil flow under the flange is faster, the oil in the cylinder can be pumped out, which leads to the internal oil level drops.

Different from model A and B, there is no disturbance area under the bottom area for model $\mathrm{C}$, the lubricating oil is sucked into the cylinder bottom, and the oil acquires an upward velocity component. So the oil could flow continuously into the cylinder without obstruction. 


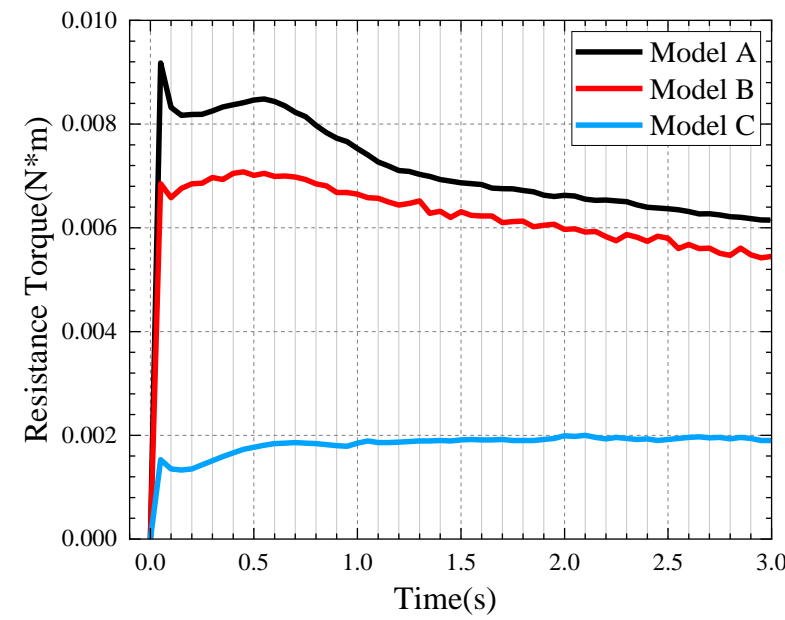

a) Resistance torque about the rotating axis

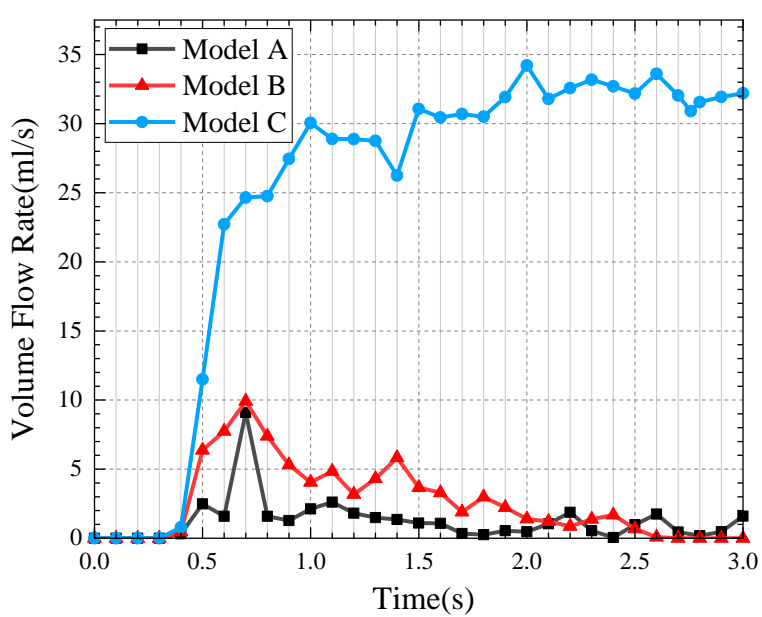

b) Volume flow rate of lubricating oil passed through the top plane

Figure 8: The time history data of the fluid resistance torque and volume flow rate.

The resistance torque of the cylinder versus time (see Fig. 8 a) is used to judge whether the steady state of flow field is reached. After $0.5 \mathrm{~s}$, due to the drop of internal oil level, the resistance torques of fluid for model $\mathrm{A}$ and $\mathrm{B}$ decrease over time, and the flow field does not achieve an equilibrium. However, the resistance torque for model $\mathrm{C}$ remains at $0.002 \mathrm{~N} \cdot \mathrm{m}$ with small fluctuations, indicates the dynamic balance of the flow field has been achieved. In addition, because the contact area of the cylinder and oil of model $\mathrm{C}$ is much smaller than that of model A and B, the fluid resistance torque of cylinder $\mathrm{C}$ is smaller than that of model $\mathrm{A}$ and B.

Monitoring the volume flow rate of lubricating oil passed through the top plane, the numerical results are shown in Fig. $8 \mathrm{~b}$. The lubricating oil reaches the top inlet at $0.4 \mathrm{~s}$. For model $\mathrm{A}$ and $\mathrm{B}$, the oil volume flow rates reached a maximum of $9 \mathrm{ml} / \mathrm{s}$ and $10 \mathrm{ml} / \mathrm{s}$ respectively at $0.7 \mathrm{~s}$, and then drop drastically to $0 \mathrm{ml} / \mathrm{s}$. As for model $\mathrm{C}$, the volume flow rate fluctuates between $30 \mathrm{ml} / \mathrm{s}$ and $35 \mathrm{ml} / \mathrm{s}$ after $1.5 \mathrm{~s}$. Compared with model $\mathrm{A}$ and $\mathrm{B}$, model $\mathrm{C}$ has an outstanding performance in oil feeding.

In conclusion, in the case of a shallow oil pool, the flange or the large diameter at the bottom can lead the oil to acquire a greater outflow velocity at the bottom, and the turbulence can hinder the oil feeding in the central area of the cylinder and restrain the increase of oil volume flow rate.

\section{EXPERIMENTS}

\subsection{Test rig}

A specific test rig is established to investigate the influence of oil-guiding cylinders, rotating speeds, and oil levels on the oil-guiding splash lubrication performance. The test rig consists of a motor, drive shaft, test device, and control system. The hollow shaft for testing driven by the motor through the coupling is mounted in the gearbox, and the oil-guiding cylinder is mounted in the bottom of the testing shaft. A detachable oil-guiding pipe, another oil-guiding device of splash lubrication, is installed on the spoke of the gear. Several oil-jet holes are opened on the hollow shaft and above the cylinder top. An oil-collecting pipe installed on the gearbox is used to collect and measure the lubricating oil splashed through the oil-jet holes. The schematic diagram and photo of the test rig for oil-guiding splash lubrication are shown in Fig. 9. 


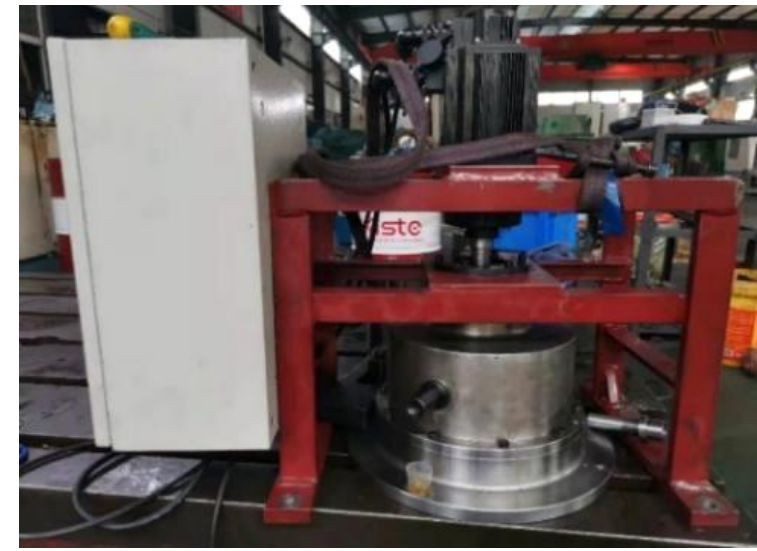

a) Test rig

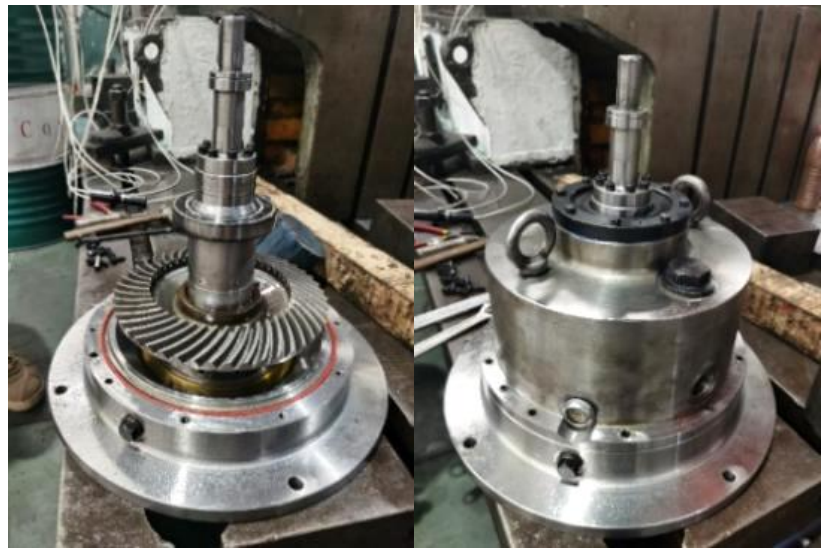

b) Gearbox

Figure 9: Test rig and gearbox.

Table I: The structure parameters of replaceable oil-guiding cylinders.

\begin{tabular}{|c|c|c|c|}
\hline Number & Hight $(\mathrm{mm})$ & Bottom diameter $(\mathrm{mm})$ & $\begin{array}{c}\text { Vertical height } \\
\text { of lower part }\end{array}$ \\
\hline 1 & 90.5 & 64 & 26 \\
\hline 2 & 100 & 18 & 17 \\
\hline 3 & 100 & 24 & 24 \\
\hline 4 & 100 & 32 & 40 \\
\hline
\end{tabular}

Four kinds of oil-guiding cylinders are investigated in this paper, as shown in Fig. 10, and their geometry parameters are shown in Table I.

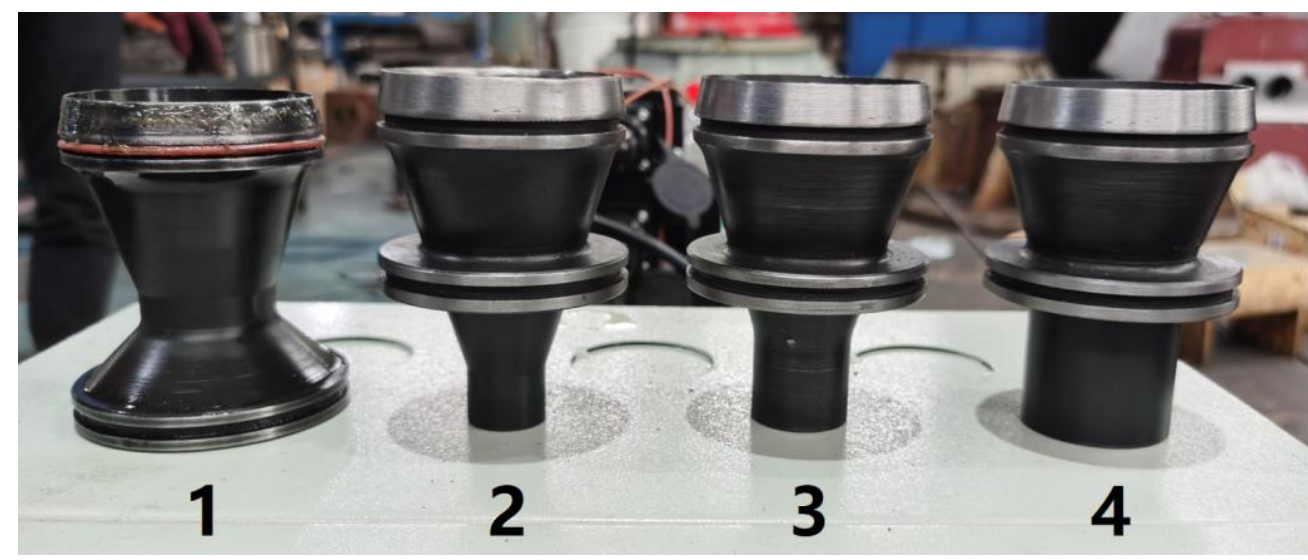

Figure 10: Replaceable oil-guiding cylinders.

\subsection{Experimental results}

The rotating speed of testing shaft was $530 \mathrm{rpm}$, the oil level $H$ was $55 \mathrm{~mm}$, and the time of one trial was about 5 minutes. To remove the influence of oil splashed from other regions, a controlled trial with the none-cylinder hollow shaft was performed first. Therefore, the amount of oil collected in the trials subtracting the oil of controlled trial was the target oil volume. Considering the computational loads, the rotation time of the hollow shaft was set to 5 seconds in numerical simulations. As stated before, the flow field at this moment has been almost stable, so it can be considered that the oil volume of the 5-second of numerical simulation is equal to the results of the 5-minute simulation. 

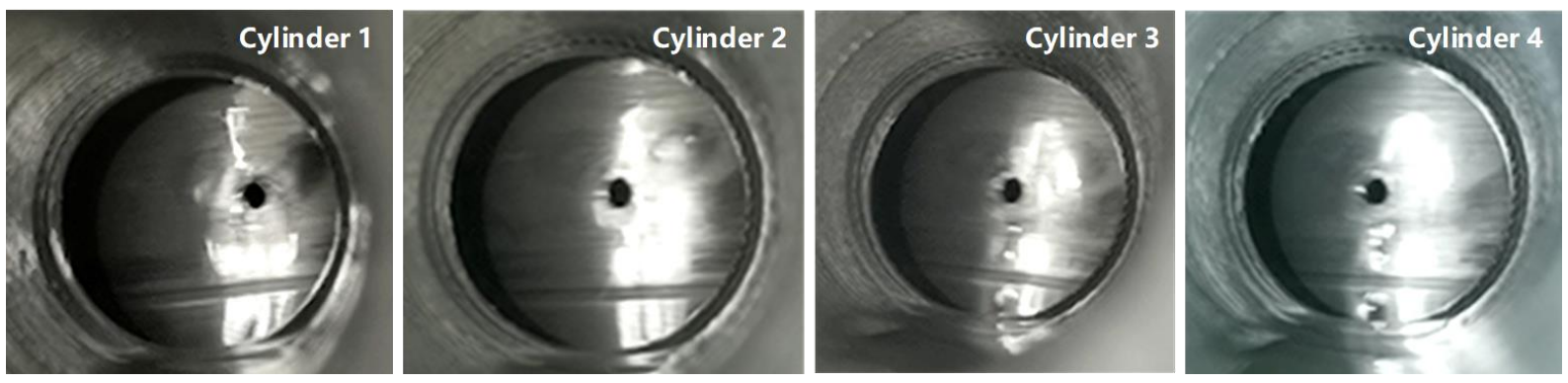

Figure 11: The oil-jet hole at the time of 1 minute.

Photos of the oil-jet hole at the time of 1 minute are shown in Fig. 11. There is no oil splashing phenomenon in the four tests at the time of 1 minute, it is consistent with the numerical results. It can be considered that the collected oil is the oil remaining in the upper part of the cylinder in the early start-up period splashed through the hole, it is consistent with the numerical results. However, traces of oil droplets flowing down below the hole with cylinder 3 and 4 can be found.

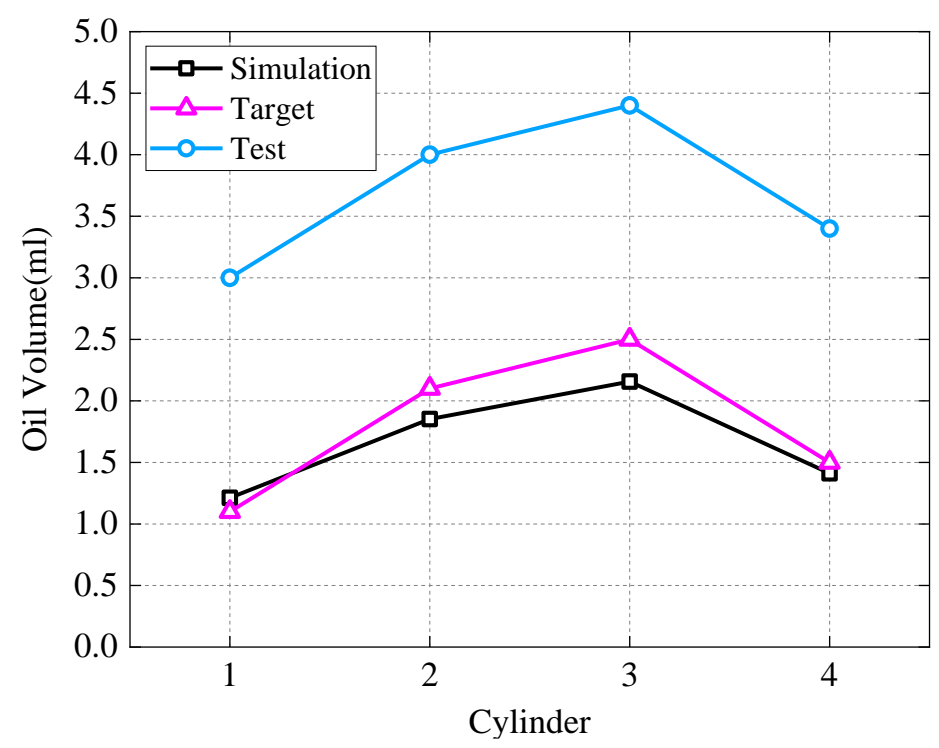

Figure 12: The collected oil volume with different cylinders.

As shown in Fig. 12, the target oil volume data is consistent with the numerical results. Cylinder 3 gives the best performance of oil feeding while cylinder 1 is the worst. The amount of oil feed by cylinders with the lower-cylindrical shaped is more than the original structure.

Therefore, cylinder 3 was exploited to carry out the experiments with different rotating speeds and oil levels. Similarly, a group of controlled trials without cylinder are performed with each operating condition to avoid the disturbances.

In the trials, the oil splashed into the oil-collecting pipe continuously at $660 \mathrm{rpm}$, but most of the collected oil came from the splashing behaviour of the gear and shaft. As Fig. 13 a, with the rotating time of $400 \mathrm{rpm}$ and $660 \mathrm{rpm}$, there is no oil splashed out from the hole. However, it is worth noting that the oil under the condition of $660 \mathrm{rpm}$ is strongly splashed from the gear and shaft as the oval mark in Fig. 13 a. As shown in Fig. 14, at 660 rpm, a large amount of oil splashes upward and collected by the oil-collecting pipe. 


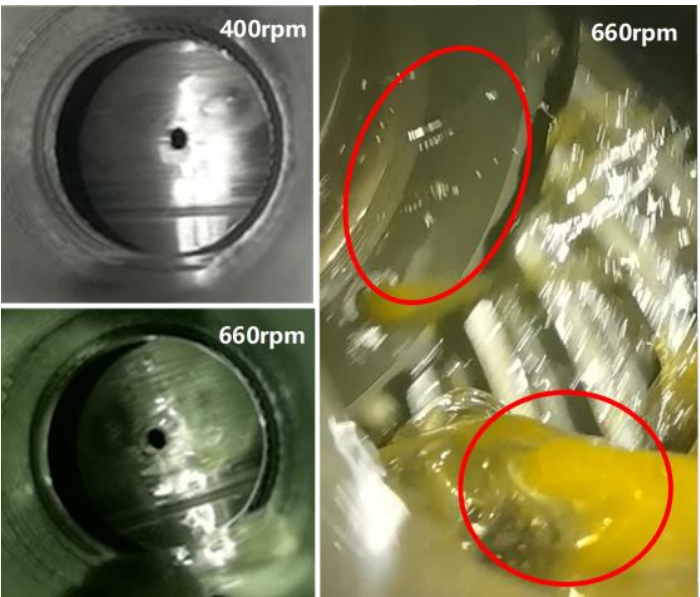

a) Different rotating speeds

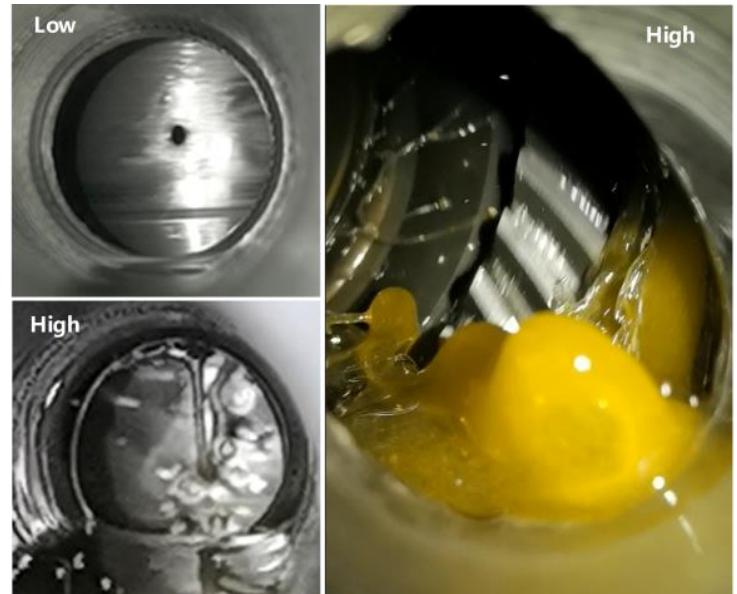

b) Different oil levels

Figure 13: The pictures of the oil-jet hole and splashing oil at 1 minute under different operating conditions.
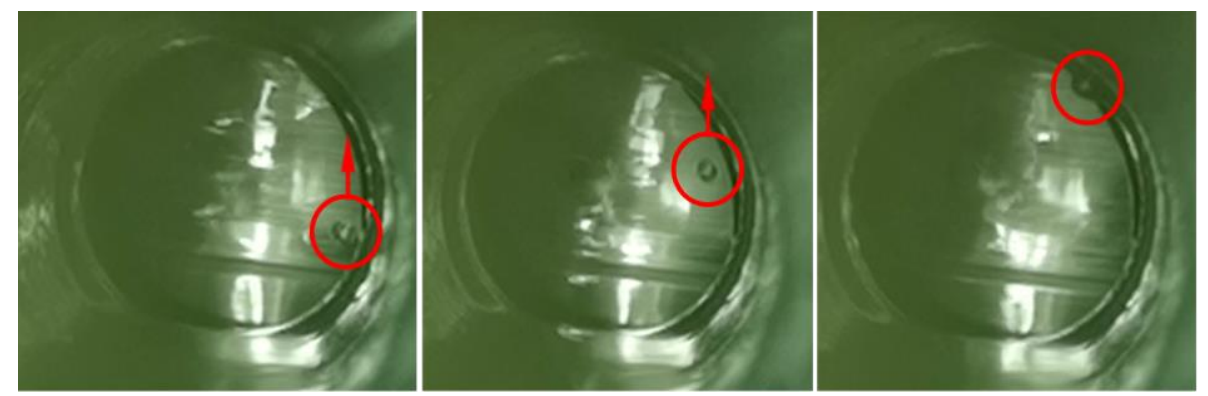

Figure 14: Splashing droplet at $660 \mathrm{rpm}$.

In terms of oil levels, three oil level heights correspond to the low, medium, and high oil levels were analysed. In Fig. 13 b, no oil is splashed through the hole in the low oil level, while the oil splashing is pretty obvious in the high oil level. Most of the oil collected in the high oil level is splashed by the action of the shaft and gear.
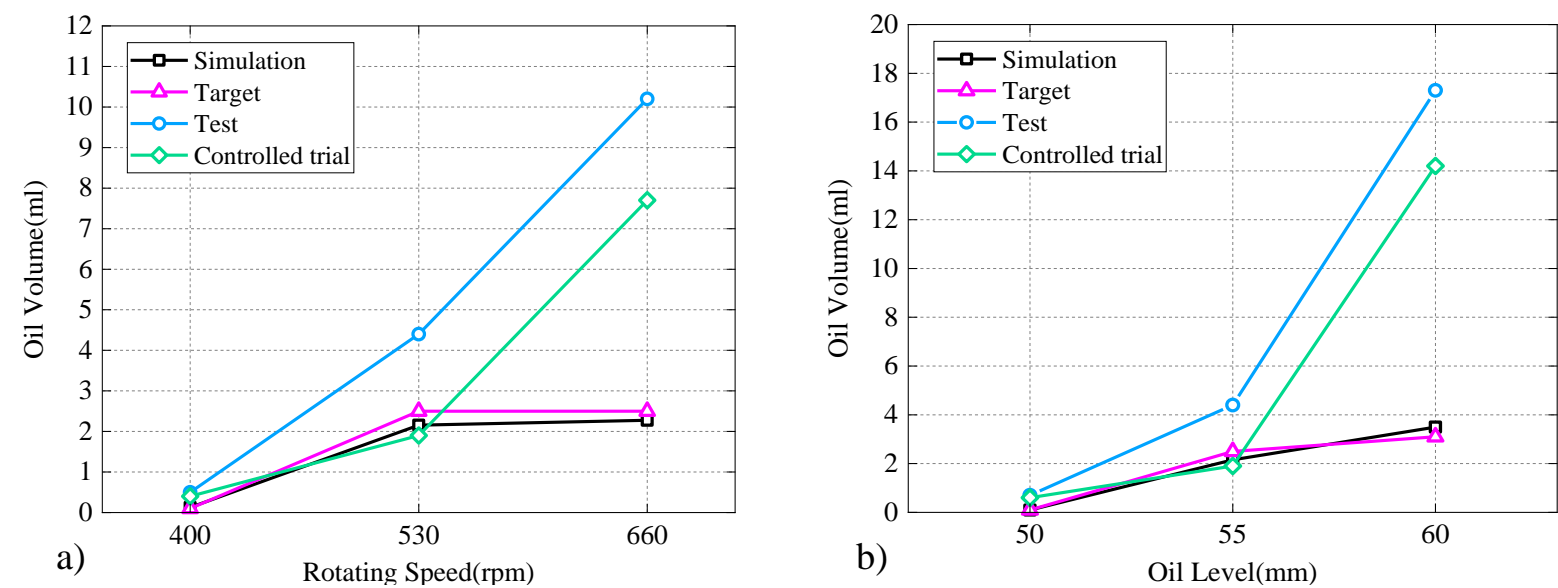

Figure 15: The collected oil volume at: a) different rotating speeds, b) different oil levels.

The experimental findings and the numerical results are listed in Fig. 15. The oil volume increases with the increase of rotating speed. Once the speed is above $530 \mathrm{rpm}$, the speed has little direct impact on the oil volume. Under low speed, the volume data are close to the simulation, but the collected oil of the controlled test increases greatly with the increase of speed, it indicates that the oil splashed by the gear and shaft increases with rotating speed. 
With respect to oil level, the numerical and experimental results show that with the increase of oil level, the collecting oil increases. As the oil level increasing, the oil close to the big end of the gear when it is at rest, the oil is contacted with the spoke and the big end. The higher the oil level is, the more collecting oil through pipes is, the greater error of the collected oil is.

To conclude, the oil-guiding cylinder with cylindrical-bottom shaped gives a better performance than the original structure. The increase of rotating speed or oil level can contribute to improve the amount of splashing oil and the lubrication performance.

\section{CONCLUSIONS}

This paper focuses on the fluid field characteristics of the oil-guiding splash lubrication. The distributions of the pressure and velocity with different oil-guiding cylinders are obtained via CFD method. Furthermore, the target volume flow rates are investigated through numerical simulation and experiment.

It reveals that the flange with a large diameter at the bottom of the oil-guiding cylinder can generate a turbulence during the rotation, and meanwhile hinder the oil supply in the central area of cylinder to weaken the oil feeding behaviour. Thus, a large bottom size of the cylinder is not suggested. In addition, the experimental findings indicate that there is an optimum bottom diameter of cylinder to maximize the volume flow rate in a particular gearbox. Critical values of the rotating speed and the oil level are existed as about $530 \mathrm{rpm}$ and $55 \mathrm{~mm}$ in this investigation, and the oil cannot reach the cylinder top unless the operating condition is above the thresholds. However, a higher speed or oil level means a greater churning power loss.

\section{ACKNOWLEDGEMENT}

This research was funded by the National Defense Preliminary Research Project of China (Grant No. KY-1044-2020-0657).

\section{REFERENCES}

[1] Daily, J. W.; Nece, R. E. (1960). Chamber dimension effects on induced flow and frictional resistance of enclosed rotating disks, Journal of Fluids Engineering, Vol. 82, No. 1, 217-232, doi: $10.1115 / 1.3662532$

[2] Mann, R. W.; Marston, C. H. (1961). Friction drag on bladed disks in housings as a function of Reynolds number, axial and radial clearance, and blade aspect ratio and solidity, Journal of Fluids Engineering, Vol. 83, No. 4, 719-723, doi:10.1115/1.3662307

[3] Boness, R. J. (1989). Churning losses of discs and gears running partially submerged in oil, Proceedings of the 1989 ASME International Power Transmission and Gearing Conference, 355359

[4] Changenet, C.; Velex, P. (2007). A model for the prediction of churning losses in geared transmissions-preliminary results, Journal of Mechanical Design, Vol. 129, No. 1, 128-133, doi: $10.1115 / 1.2403727$

[5] Gorla, C.; Concli, F.; Stahl, K.; Höhn, B.-R.; Klaus, M.; Schultheiß, H.; Stemplinger, J.-P. (2012). CFD simulations of splash losses of a gearbox, Advances in Tribology, Vol. 2012, Paper 616923, 10 pages, doi: $10.1155 / 2012 / 616923$

[6] Czyz, Z.; Karpinski, P. (2020). Aerodynamic characteristics of the X-tail stabilizer in a hybrid unmanned aircraft, International Journal of Simulation Modelling, Vol. 19, No. 4, 631-642, doi:10.2507/IJSIMM19-4-534

[7] Marchesse, Y.; Changenet, C.; Ville, F.; Velex, P. (2011). Investigations on CFD simulations for predicting windage power losses in spur gears, Journal of Mechanical Design, Vol. 133, No. 2, Paper 024501, 7 pages, doi:10.1115/1.4003357 
[8] Dai, Y.; Wu, W.; Zhou, H. B.; Zhang, J.; Ma, F. Y. (2018). Numerical simulation and optimization of oil jet lubrication for rotorcraft meshing gears, International Journal of Simulation Modelling, Vol. 17, No. 2, 318-326, doi:10.2507/IJSIMM17(2)CO6

[9] Dai, Y.; Ma, F.; Zhu, X.; Ouyang, B. (2020). Development of an analytical model to estimate the churning power losses of a spiral bevel gear, Tribology International, Vol. 151, Paper 106536, 9 pages, doi:10.1016/j.triboint.2020.106536

[10] Ouyang, B.; Ma, F.; Dai, Y.; Zhang, Y. (2021). Numerical analysis on heat-flow-coupled temperature field for orthogonal face gears with oil-jet lubrication, Engineering Applications of Computational Fluid Mechanics, Vol. 15, No. 1, 762-780, doi:10.1080/19942060.2021.1918259

[11] Gorla, C.; Concli, F.; Stahl, K.; Hohn, B.-R.; Michaelis, K.; Schultheis, H.; Stemplinger, J.-P. (2013). Hydraulic losses of a gearbox: CFD analysis and experiments, Tribology International, Vol. 66, 337-344, doi:10.1016/j.triboint.2013.06.005

[12] Concli, F.; Gorla, C. (2013). Influence of lubricant temperature, lubricant level and rotational speed on the churning power loss in an industrial planetary speed reducer: computational and experimental study, International Journal of Computational Methods and Experimental Measurements, Vol. 1, No. 4, 353-366, doi:10.2495/CMEM-V1-N4-353-366

[13] Concli, F.; Gorla, C.; Della Torre, A.; Montenegro, G. (2015). Churning power losses of ordinary gears: a new approach based on the internal fluid dynamics simulations, Lubrication Science, Vol. 27, No. 5, 313-326, doi: $10.1002 / 1 \mathrm{~s} .1280$

[14] Hu, X.; Jiang, Y.; Luo, C.; Feng, L.; Dai, Y. (2019). Churning power losses of a gearbox with spiral bevel geared transmission, Tribology International, Vol. 129, 398-406, doi:10.1016/ j.triboint.2018.08.041

[15] Liu, H.; Jurkschat, T.; Lohner, T.; Stahl, K. (2017). Determination of oil distribution and churning power loss of gearboxes by finite volume CFD method, Tribology International, Vol. 109, 346354, doi:10.1016/j.triboint.2016.12.042

[16] Laruelle, S.; Fossier, C.; Changenet, C.; Ville, F.; Koechlin, S. (2017). Experimental investigations and analysis on churning losses of splash lubricated spiral bevel gears, Mechanics \& Industry, Vol. 18, No. 4, Paper 412, 10 pages, doi:10.1051/meca/2017007

[17] Boni, J.-B.; Neurouth, A.; Changenet, C.; Ville, F. (2017). Experimental investigations on churning power losses generated in a planetary gear set, Journal of Advanced Mechanical Design, Systems, and Manufacturing, Vol. 11, No. 6, Paper 17-00196, 12 pages, doi:10.1299/ jamdsm.2017jamdsm0079

[18] Chen, S.-W.; Matsumoto, S. (2016). Influence of relative position of gears and casing wall shape of gear box on churning loss under splash lubrication condition-some new ideas, Tribology Transactions, Vol. 59, No. 6, 993-1004, doi:10.1080/10402004.2015.1129568

[19] Peng, Q.; Gui, L.; Fan, Z. (2018). Numerical and experimental investigation of splashing oil flow in a hypoid gearbox, Engineering Applications of Computational Fluid Mechanics, Vol. 12, No. 1, 324-333, doi:10.1080/19942060.2018.1432506

[20] Concli, F.; Gorla, C. (2016). Numerical modeling of the power losses in geared transmissions: Windage, churning and cavitation simulations with a new integrated approach that drastically reduces the computational effort, Tribology International, Vol. 103, 58-68, doi:10.1016/ j.triboint.2016.06.046

[21] Hatami, M.; Ganji, D. D. (2014). Motion of a spherical particle in a fluid forced vortex by DQM and DTM, Particuology, Vol. 16, 206-212, doi:10.1016/j.partic.2014.01.001 